\title{
ENSURING THE RELIABILITY AND PERFORMANCE CRITERIAS OF CRANKSHAFTS
}

\author{
Alexey KOTLIAR ${ }^{1}$, Magomediemin GASANOV ${ }^{2}$, Yevheniia BASOVA ${ }^{3}$, \\ Olga PANAMARIOVA ${ }^{4}$, Sergii GUBSKYI \\ National Technical University «Kharkov Polytechnic Institute», 2, Kyrpychova str., 61002, Kharkov, Ukraine \\ 'e-mail: Alexeykotliar@gmail.com; ${ }^{2}$ e-mail: kh.hpi.hasanov@gmail.com; \\ 3e-mail: e.v.basova.khpi@gmail.com, ${ }^{4}$ e-mail: agattaold@gmail.com, ${ }^{5}$ e-mail: gubskiy@inbox.ru
}

\section{Abstract}

The issues of efficiency improvement of manufacturing crankshafts in order to ensure their reliability and performance criteria are the priorities in modern production of internal combustion engines. Using the capabilities of modern special grinding machines can improve the quality of machining and obtain the necessary running characteristics of crankshafts. In work the questions connected with development of a method of calculation of rigidity of crankshafts for increase of accuracy of their machining, reliability and performance criteria's are considered. Based on the proposed methodology, numerical calculations have performed and the possibility of determining the deflections and crankshafts rigidity in any section have been justified. The original construction of the following grinding steady rest for CNC grinding machines specified for machining the crankshaft main bearing journal and connecting rod journal is proposed. The construction design of the device allows for compensating the influence of the cutting force on the elastic strain of the part, depending on the change in its rigidity. The practical value of the research includes in develop recommendations for determining the optimal parameters for the round infeed grinding cycle of the crank pins from the point of view of productivity and accuracy.

Keywords: crankshaft, initial parameters method, reliability, grinding machine, rest.

\section{INTRODUCTION}

Modern machine industry is characterized by increasing requirements for quality assurance and precision manufacturing of critical machine parts. The reliability of operation of any machine is directly proportional to the break-even reliability of its components and mechanisms.

The crankshaft is considered one of the most critical parts of an internal combustion engine since it solves the problem of converting translatory motion from engine piston to rotational moment [14]. It should be noted that this element of the crank mechanism is a constructively and technologically complex member. This is why high requirements to the accuracy of manufacturing crankshafts are being put demanded. Among the main requirements should be noted:

- the accuracy of diametrical dimensions of the crankshaft main bearing journals and crankshaft rod journals IT6 (less often IT5);

- the form tolerance of the crankshaft main bearing journals and crankshaft rod journals are not more than 0.3 of the permissible error for the diameter of these crank pins;

- deviations from alignment of the location of the crankshaft main bearing journals not more than
$0,02 \mathrm{~mm}$, from the parallelism of the axes of the crankshaft main bearing journals and crankshaft rod journals not more than $0,015 \mathrm{~mm}$ on the length of the crank pin;

- hopping of the crankshaft main bearing journals relative to the axis of the center holes in the range $0,01 \ldots 0,03 \mathrm{~mm}$;

- surface roughness of the crankshaft main bearing journals and crankshaft rod journals in the range $\mathrm{Ra}=0.08 \ldots 0.32 \mu \mathrm{m}$.

When processing workpiece of crankshafts, the structure of the construction of the technological process operations and the choice of equipment depend on the volume of output products. At the same time, in any process, the state of the base surfaces and the finishing operations for the formation of high precision processing are given special attention [1]. To reduce deformations when processing flexible crankeds, distributing and other shafts, in addition to the rests, special machines with a central or double-sided drive are used.

As of today for final polishing and finishing processing CNC grinding machines have found the greatest application [2]. These machines implement high quality and precision of parts processing, but at the same time, their work as the dynamic systems has not been studied enough. This involves 
difficulties in the development of new equipment, increasing its accuracy and chatter stability. In this regard, studies and detailed calculations of the rigidity of all elements of the technological system become necessary. When developing a general model of metal-cutting machine, it is important to take into account the dynamics of each elements of the dynamic system. It is needed to know the rigidity of each element for determine their dynamic characteristics [5]. The total rigidity of the machine's dynamic system consists of a series and parallel connection of elements. This value depends on the rigidity of the workpiece, as often the rigidity of the workpiece is much less than the rigidity of other elements of the machine's dynamic system.

From the analysis of modern information sources, the actual task of ensuring the accuracy and quality of manufacturing critical parts of machines [6-8] such as a crankshaft that affect the reliability of the overall mechanism during working was defined.

Author of paper [6], taking into account the qualitative characteristics of the crankshaft, have presented the results of the analysis of how sea waves affect the angular speed of a propulsion. In the article, the method of assessing the state of the ship's engine was considered. Implementation of the method is possible, including with the appropriate qualitative characteristics of the crankshaft.

In article [7] there is described the details of the method designed to determine parameters of vehicle's internal combustion engine with compression ignition (CI) during road tests. The method requires simultaneous measurements for the crankshaft rotation frequency, fuel pressure in the injector, pressure in the combustion chamber, air pressure and temperature in the intake system [7]. It is not possible to obtain an adequate mathematical model using this method if the crankshaft does not meet the criteria for quality and accuracy.

In the article [9] authors have considered the crankshaft (taking into account the fact that the part corresponds to high quality and accuracy characteristics) and presented the model of the crankshaft taking into account the coupling of bending and torsional vibrations. The paper is summarized by giving conclusions about the analysis of crankshaft systems with a dynamic eliminator of vibrations and their modelling.

The authors of paper [10] noted that crankshaftspringing characteristics are one of the most important from the ships' main engines reliability point of view. The adequacy of this characteristic depends on the quality and accuracy of the crankshaft machining on the working machine. The authors noted that development of the analysis methods of crankshaft's stiffness characteristics is the first step of planned monitoring system that will be able to verify crankshaft-springing characteristics by continuous measurements of the crankshaft free-end's axial deformations [10].

Thus, many researchers investigate the behavior of the crankshaft during the working of the complete mechanism and try to increasing the operational characteristics both the details and the mechanism as a whole. However, the actual task remains to make initially high-quality engineering product. For this, it is important to accept and process the specifications for the production of the crankshaft.

Thus, the purpose of this article is to propose methods for calculating the rigidity of crankshafts for improving the accuracy of their processing, reliability and performance indexes.

\section{CALCULATION OF THE CRANKSHAFT RIGIDITY USING THE INITIAL PARAMETERS}

To determine the deformations in multidiameter parts that work under the conditions of applied loads, it was decided to apply a modified initial parameters method [1, 7, 11-12]. The essence of the method consists in changing the stepped part with an equivalent piece of constant rigidity.

The analytical model for determining the deformation movements and the crankshaft rigidity is shown in Fig. 1.

The characteristic property of the crankshafts is that the connecting rod journals, as well as the webs connecting them with the crankshaft main bearing journals, have relevance an eccentricity to the axes of the crankshaft main bearing journals and the shaft as a whole. At the same time, their unbalanced masses will cause significant dynamic loads during grinding. Therefore, to study the dynamic system, it is important to determine the value of the crankshaft rigidity. The load from the cutting force in the form of the resultant force $P$ will be applied in the middle of the crank pin (see Fig.1, cond.I).

We divide the crankshaft into three equal parts (see Fig.1, cond.I-III), applying the corresponding force factors $Q$ (lateral force) and $M$ (bending moment) in the cut points, which in our case can be found by the formula (1): on condition $x<a$ :

$$
Q_{i}=\frac{P \cdot(L-a)}{L}, \text { and } M_{i}=\frac{P \cdot(L-a) \cdot I_{i}}{L},
$$

on condition $x>a$ :

$$
Q_{i}=\frac{P \cdot(L-a)}{L}-P, \text { and } M_{i}=\frac{P \cdot a}{L \cdot\left(L-I_{i}\right)},
$$

where

$a$ - coordinate of force application, (mm);

$I_{i}$ - coordinate of the corresponding section, (mm).

After that, it is necessary to multiply the obtained values $Q_{i}$ and $M_{i}$ by the corresponding reduction factors determined by the formula (2):

$$
\beta_{i}=\frac{I_{0}}{I_{i}}
$$




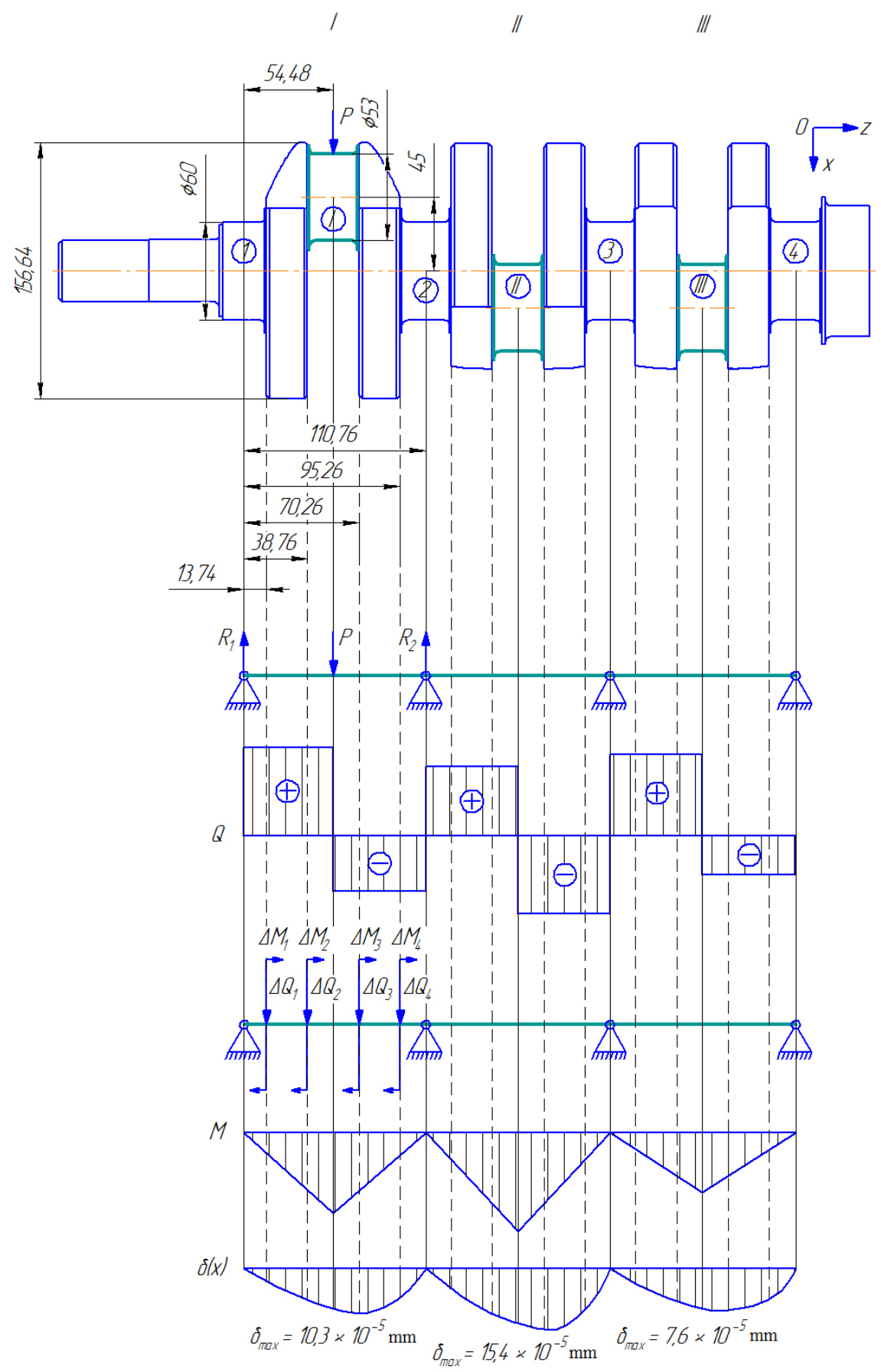

Fig. 1. The crankshaft analytical model

where

$I_{0}$ - the equivalent moment of inertia, equal to the moment of inertia of one of the sections to which the reduction takes place, $\left(\mathrm{mm}^{4}\right)$;

$I_{i}$ - inertia moment of the corresponding area, $\left(\mathrm{mm}^{4}\right)$ [11].

For cylindrical sections $I_{i}$ it corresponds to:

$$
I_{i}=\frac{\pi \cdot d_{i}^{4}}{64},
$$

where

$d_{i}$ - diameter of the corresponding section, (mm).

For eccentric surfaces of crankshaft connecting rod journal $I_{i}$ will be determined as:

$$
I_{i}=\frac{\pi \cdot d_{i}^{4}}{64} \cdot e^{2} \cdot \frac{\pi \cdot d_{i}^{4}}{4},
$$

where

$e$ - eccentricity between the axis of the connecting rod bearing journal and main bearing journal, $(\mathrm{mm})$;

$d_{i}$ - diameter of the crankshaft pin, $(\mathrm{mm})$.

For webs connecting the crankshaft neck and crankshaft pin $I$ can be defined as:

$$
I_{i}=\frac{b \cdot h^{3}}{12} \cdot \cos ^{2} \alpha+\frac{h \cdot b^{3}}{12} \cdot \sin \alpha+e_{l}^{2} \cdot \frac{\pi \cdot d_{i}^{2}}{4},
$$

where

$b$ - width of web, (mm); 
$h$ - height of web, (mm);

$e_{1}-$ eccentricity between the axis of the crankshaft neck and the web, $(\mathrm{mm})$;

$\alpha$ - corresponding rotation angle of the crankshaft; $d_{i}$ - diameter of the crankshaft neck (main bearing journal), (mm).

From the formula (5) it is seen that the inertia moment of the webs varies depending on the rotation angle of the crankshaft. Its value is shown in Table 1.

Table 1. Values of inertia moments of crankshaft

\begin{tabular}{|c|c|c|c|c|c|}
\hline$\alpha,\left(^{\circ}\right)$ & $\begin{array}{c}\mathrm{I} \cdot 10^{-7}, \\
\left(\mathrm{~mm}^{4}\right)\end{array}$ & $\alpha,{ }^{\circ}$ & $\begin{array}{c}\mathrm{I} \cdot 10^{-7}, \\
\left(\mathrm{~mm}^{4}\right)\end{array}$ & $\alpha,{ }^{\circ}$ & $\begin{array}{c}\mathrm{I} \cdot 10^{-7}, \\
\left(\mathrm{~mm}^{4}\right)\end{array}$ \\
\hline 20 & 4,175 & 140 & 3,84 & 260 & 3,21 \\
\hline 40 & 3,84 & 160 & 4,175 & 280 & 3,21 \\
\hline 60 & 3,459 & 180 & 4,308 & 300 & 3,459 \\
\hline 80 & 3,21 & 200 & 4,175 & 320 & 3,84 \\
\hline 100 & 3,21 & 220 & 3,84 & 340 & 4,175 \\
\hline 120 & 3,459 & 240 & 3,459 & 360 & 4,308 \\
\hline
\end{tabular}

As a result of joining-up the split parts we obtain a beam of constant cross section, which is loaded with the given external loads. At the junction points, it is important to take into account the additional forces $\Delta Q$ and the moment $\Delta M$, whose values are determined by formula (6):

$$
\begin{aligned}
& \Delta M_{i}=M_{i} \cdot\left(\beta_{i}-\beta_{i-1}\right), \\
& \Delta Q_{i}=Q_{i} \cdot\left(\beta_{i}-\beta_{i-1}\right),
\end{aligned}
$$

In order to determine the displacements in the resulting equivalent beam, an universal elastic-line equation has been used [11], which has the form (7):

$$
\begin{aligned}
& \delta(x)=w_{0}+\theta_{0} x+\frac{1}{E l_{i}} \times \\
& \times\left[\sum_{n=1}^{i} M_{i} \cdot \frac{\left(x-l_{i}\right)^{2}}{2}+\sum_{n=1}^{i} Q_{i} \cdot \frac{\left(x-l_{i}\right)^{3}}{6}+R \cdot \frac{x^{3}}{6}\right]^{(7)}
\end{aligned}
$$

where

$w_{0}$ - initial deflection in the left support, $(\mathrm{mm})$;

$\theta_{0}$ - initial rotation angle in left support, $\left({ }^{\circ}\right)$;

$x$ - running coordinate, $(\mathrm{mm})$;

$E-$ Young's modulus, $\left(\mathrm{N} / \mathrm{mm}^{2}\right)$;

$M_{i}$ - bending moment at the corresponding section,

$(\mathrm{N} \cdot \mathrm{mm})$;

$l$ - coordinate of the relevant section, $(\mathrm{mm})$;

$Q_{i}$ - transverse force at the relevant section, (N);

$R$ - reaction in the left support, $(\mathrm{N})$.

The crankshaft is not a rigid part, and the requirements for accuracy and roughness of its surfaces are quite high. Given this fact, two intermediate supports in the form of rests were proposed to meet these quality requirements (Fig. 1).

At the first stage of solving the task of ensuring the quality of crankshaft processing, the equation of the elastic line for the first part of work-piece have been written (8):

$$
\begin{aligned}
& \delta(x)=w_{0}+\theta_{0} x+\frac{1}{E l_{i}} \times \\
& \times\left[\begin{array}{l}
\frac{P \cdot(L-a) \cdot l_{1}}{L} \cdot \frac{\left(x-l_{1}\right)^{2}}{2}+\frac{P \cdot(L-a) \cdot l_{2}}{L} \times \\
\times\left(\frac{l_{1}}{l_{2}}-\frac{l_{1}}{l_{1}}\right) \cdot \times \frac{\left(x-l_{2}\right)^{2}}{2}+\frac{P \cdot a}{L \cdot\left(L-l_{3}\right)} \times \\
\left(\begin{array}{l}
\left.\frac{l_{1}}{l_{3}}-\frac{l_{1}}{l_{2}}\right) \cdot \frac{\left(x-l_{3}\right)^{2}}{2}+\frac{P \cdot a}{L \cdot\left(L-l_{4}\right)} \cdot\left(\frac{l_{1}}{l_{4}}-\frac{l_{1}}{l_{3}}\right) \times \\
+\frac{P \cdot(L-a)}{L} \cdot\left(\frac{l_{1}}{l_{2}}-\frac{l_{1}}{l_{1}}\right) \cdot \frac{\left(x-l_{2}\right)^{3}}{6}+ \\
+\left(\frac{P \cdot(L-a)}{L}-P\right) \cdot\left(\frac{l_{1}}{l_{3}}-\frac{l_{1}}{l_{2}}\right) \cdot \frac{\left(x-l_{1}\right)^{3}}{6}+ \\
+\left(\frac{P \cdot(L-a)}{L}-P\right) \cdot\left(\frac{l_{1}}{l_{4}}-\frac{l_{1}}{l_{3}}\right) \cdot \frac{\left(x-l_{4}\right)^{3}}{6}+\frac{P}{2} \cdot \frac{x^{3}}{6}
\end{array}\right]
\end{array}\right.
\end{aligned}
$$

Note that the equation of the elastic line for the second and third part of the crankshaft will be similar to the equation of the elastic line of the first part of the crankshaft, the difference will be only in the values of the lengths of some sections.

The rigidity of the workpiece is determined without taking into account the rigidity of the supports, as well as the spindle, stock head, deadhead and rests. Therefore, the initial rotation angle in the left support is found from the initial conditions $x=L ; w_{0}=0 ; E=2 \cdot 105 \mathrm{~N} / \mathrm{mm}^{2} ; P=157 \mathrm{~N}$. From here, the equation (9) was obtained:

$$
\left.\begin{array}{l}
\theta_{0}=-\frac{1}{E l_{i} L} \times \\
\frac{P \cdot(L-a) \cdot l_{1}}{L} \cdot \frac{\left(L-l_{1}\right)^{2}}{2}+\frac{P \cdot(L-a) \cdot l_{2}}{L} \times \\
\times\left(\frac{l_{1}}{l_{2}}-\frac{l_{1}}{l_{1}}\right) \cdot \frac{\left(L-l_{2}\right)^{2}}{2}+\frac{P \cdot a}{L \cdot\left(L-l_{3}\right)} \times \\
\times\left(\frac{l_{1}}{l_{3}}-\frac{l_{1}}{l_{2}}\right) \cdot \frac{\left(L-l_{3}\right)^{2}}{2}+\frac{P \cdot a}{L \cdot\left(L-l_{4}\right)} \cdot\left(\frac{l_{1}}{l_{4}}-\frac{l_{1}}{l_{3}}\right) \times \\
\times \frac{\left(L-l_{4}\right)^{2}}{2}+\frac{P \cdot(L-a)}{L} \cdot \frac{\left(L-l_{1}\right)^{3}}{6}+ \\
+\frac{P \cdot(L-a)}{L} \cdot\left(\frac{l_{1}}{l_{2}}-\frac{l_{1}}{l_{1}}\right) \cdot \frac{\left(L-l_{2}\right)^{3}}{6}+ \\
+\left(\frac{P \cdot(L-a)}{L}-P\right) \cdot\left(\frac{l_{1}}{l_{3}}-\frac{l_{1}}{l_{2}}\right) \cdot \frac{\left(L-l_{3}\right)^{3}}{6}+ \\
+\left(\frac{P \cdot(L-a)}{L}-P\right) \cdot\left(\frac{l_{1}}{l_{4}}-\frac{l_{1}}{l_{3}}\right) \cdot \frac{\left(L-l_{4}\right)^{3}}{6}+\frac{P}{2} \cdot \frac{L^{3}}{6}
\end{array}\right]
$$

At this stage, it is possible to determine the amount of deflection of the crankshaft at any place in the longitudinal and in the cross sections, depending on the angle of rotation. To find the deflection in the general equation of an elastic line, it is necessary to take only those components of the 
force factors that lie to the left of the required crosssection.

After finding the deflections, the rigidity of the corresponding sections was founded, in accordance with formula (10)

$$
C_{x}=\frac{P}{\delta(x)} .
$$

The results of calculations of deflections and roughness's of connecting rod bearing journals depending on the rotation angle of the crankshaft have presented in Table 2.

Table 2. The calculated values of deflections and stiffness's of connecting rod journal

\begin{tabular}{|c|c|c|c|c|c|}
\hline \multicolumn{6}{|c|}{ First crank pin } \\
\hline $\begin{array}{l}\alpha, \\
\left({ }^{\circ}\right)\end{array}$ & $\begin{array}{l}\delta \cdot 10^{5}, \\
(\mathrm{~mm})\end{array}$ & $\begin{array}{l}\mathrm{C} \cdot 10^{-5}, \\
(\mathrm{~N} / \mathrm{mm})\end{array}$ & $\begin{array}{l}\alpha \\
\left(^{\circ}\right)\end{array}$ & $\begin{array}{l}\delta \cdot 10^{5}, \\
(\mathrm{~mm})\end{array}$ & $\begin{array}{l}\mathrm{C} \cdot 10^{-5}, \\
(\mathrm{~N} / \mathrm{mm})\end{array}$ \\
\hline 1 & 2 & 3 & 4 & 5 & 6 \\
\hline 20 & 10,07 & 15,49 & 200 & 10,08 & 15,48 \\
\hline 40 & 10,15 & 15,37 & 220 & 10,16 & 15,35 \\
\hline 60 & 10,21 & 15,28 & 240 & 10,22 & 15,26 \\
\hline 80 & 10,23 & 15,25 & 260 & 10,24 & 15,23 \\
\hline 100 & 10,19 & 15,31 & 280 & 10,18 & 15,32 \\
\hline 120 & 10,10 & 15,45 & 300 & 10,10 & 15,45 \\
\hline 140 & 10,02 & 15,57 & 320 & 10,01 & 15,58 \\
\hline 160 & 9,986 & 15,62 & 340 & 9,672 & 16,13 \\
\hline 180 & 9,980 & 15,63 & 360 & 9,985 & 15,62 \\
\hline \multicolumn{6}{|c|}{ Second crank pin } \\
\hline 20 & 14,93 & 10,45 & 200 & 14,98 & 10,41 \\
\hline 40 & 14,94 & 10,44 & 220 & 14,95 & 10,43 \\
\hline 60 & 15,04 & 10,37 & 240 & 15,05 & 10,37 \\
\hline 80 & 15,21 & 10,26 & 260 & 15,20 & 10,26 \\
\hline 100 & 15,27 & 10,22 & 280 & 15,33 & 10,18 \\
\hline 120 & 15,35 & 10,16 & 300 & 15,38 & 10,14 \\
\hline 140 & 15,29 & 10,20 & 320 & 15,33 & 10,18 \\
\hline 1 & 2 & 3 & 4 & 5 & 6 \\
\hline 160 & 15,21 & 10,26 & 340 & 15,20 & 10,26 \\
\hline 180 & 15,09 & 10,34 & 360 & 15,07 & 10,35 \\
\hline \multicolumn{6}{|c|}{ Third crank pin } \\
\hline 20 & 6,542 & 23,85 & 200 & 6,544 & 23,84 \\
\hline 40 & 6,001 & 26,00 & 220 & 5,982 & 26,08 \\
\hline 60 & 5,766 & 27,06 & 240 & 5,780 & 26,99 \\
\hline 80 & 6,030 & 25,87 & 260 & 6,041 & 25,82 \\
\hline 100 & 6,624 & 23,55 & 280 & 6,621 & 23,56 \\
\hline 120 & 7,203 & 21,66 & 300 & 7,221 & 21,60 \\
\hline 140 & 7,537 & 20,70 & 320 & 7,558 & 20,64 \\
\hline 160 & 7,519 & 20,75 & 340 & 7,557 & 20,64 \\
\hline 180 & 7,165 & 21,77 & 360 & 7,168 & 21,76 \\
\hline
\end{tabular}

\section{DETERMINATION OF THE \\ CRANKSHAFT RIGIDITY BY THE SIMULATION APPROACH}

With the invention of modern computer technology, the analysis of complex details has become simpler [1316].

To determine the deflection of the connecting rod journal of the crankshaft under the action of the cutting force during grinding the simulation method was used. This was made possible by minimizing the simplifications of the mathematical model and increasing the accuracy of the calculation of force factors. The model of the crankshaft with the specified fastening and the action vectors of the cutting forces is shown in Fig. 2.

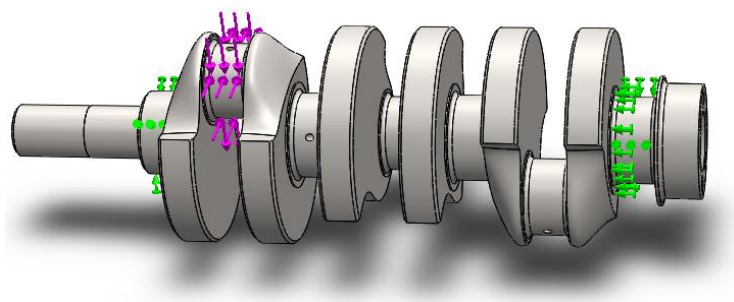

Fig. 2. Three-dimensional model of the crankshaft

Initial conditions for modeling:

- material of the part - steel 40HNMA;

- fixing type - rigid;

- the cutting force was decomposed into two components: $P_{y}=142,6 \mathrm{~N}, P_{z}=64,8 \mathrm{~N}$.

The diagram of the crankshaft model deflections under the influence of the cutting force is shown in Fig. 3.

The total results of the deflections values and rigidities of connecting rod journal (Table 3), depending on the angle of the crankshaft rotation, were determined using the simulation method.

\section{ANALYSIS OF SIMULATION RESULTS}

As can be seen from the tables 2 and 3, the calculation of the rigidity and elastic deformation of crankshafts by the initial parameters method ensures a sufficiently high convergence with the simulation results.

For further analysis, the data obtained at the stage of simulation modelling were accepted. This made it possible to plot the out-of-roundness profile of the cross section strain of the crankshaft pin under the influence of the cutting force. In Fig. 4 shows the out-of-roundness profile for the most dangerous, from the point of view of the form accuracy, the second crank pin.

From Fig. 4 it can be seen that, depending on the crankshaft rotation angle during grinding, its strain has different characteristics (by a factor of $1.5)$, thereby directly affecting the accuracy of the shape of the machined crank pin.

Taking into account possible changes in the cutting conditions (namely, their intensification), additional studies were carried out to obtain an index of the cross section strain of the crankshaft rod journal $\delta$ depending on the resultant cutting 


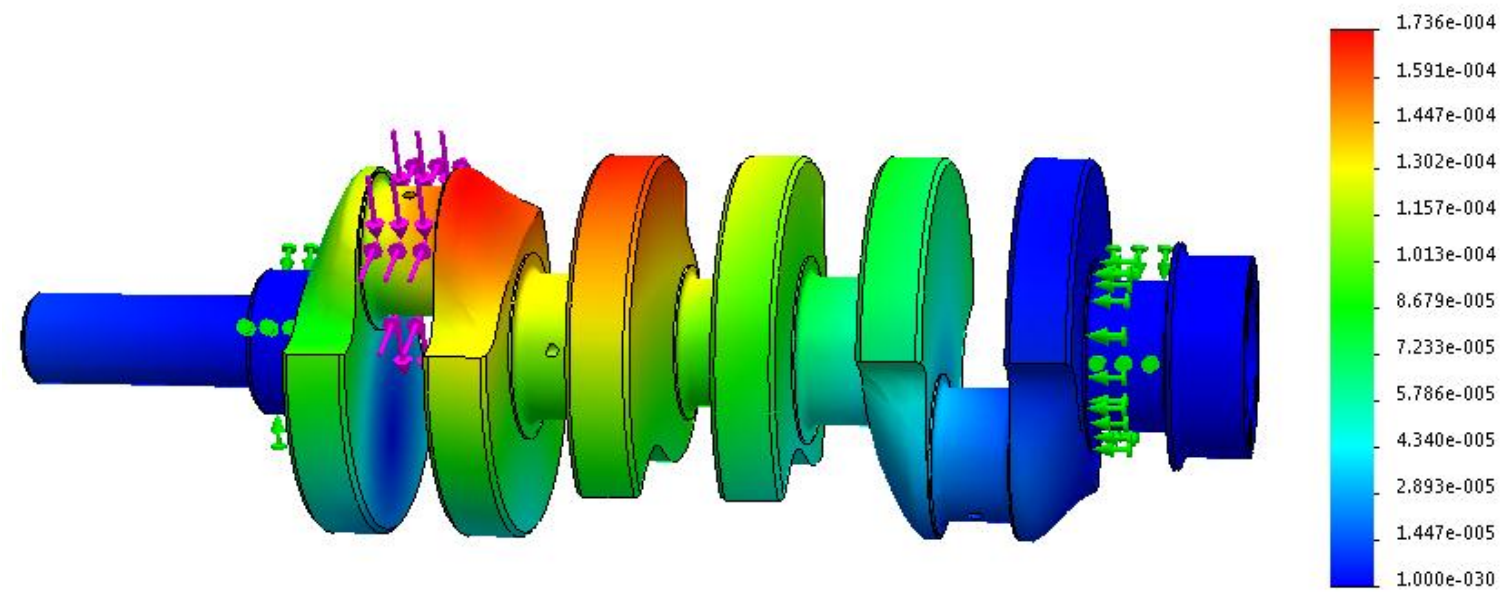

Fig. 3. Strain diagram of the crankshaft model

Table 3. The total results of the deflections values and rigidities of connecting rod journal

\begin{tabular}{|c|c|c|c|c|c|}
\hline \multicolumn{7}{|c|}{ First crank pin } \\
\hline $\begin{array}{c}\alpha, \\
\left(^{\circ}\right)\end{array}$ & $\begin{array}{c}\delta \cdot 10^{5}, \\
(\mathrm{~mm})\end{array}$ & $\begin{array}{c}\mathrm{C} \cdot 10^{-5}, \\
(\mathrm{~N} / \mathrm{mm})\end{array}$ & $\begin{array}{c}\alpha, \\
\left.{ }^{\circ}\right)\end{array}$ & $\begin{array}{c}\delta \cdot 10^{5}, \\
(\mathrm{~mm})\end{array}$ & $\begin{array}{c}\mathrm{C} \cdot 10^{-5}, \\
(\mathrm{~N} / \mathrm{mm})\end{array}$ \\
\hline 1 & 2 & 3 & 4 & 5 & 6 \\
\hline 20 & 15,81 & 9,930 & 200 & 15,83 & 9,92 \\
\hline 40 & 15,93 & 9,854 & 220 & 15,95 & 9,842 \\
\hline 60 & 16,04 & 9,790 & 240 & 16,04 & 9,787 \\
\hline 80 & 16,05 & 9,780 & 260 & 16,08 & 9,767 \\
\hline 100 & 16,00 & 9,814 & 280 & 15,99 & 9,821 \\
\hline 120 & 15,85 & 9,906 & 300 & 15,85 & 9,906 \\
\hline 140 & 15,73 & 9,979 & 320 & 15,72 & 9,986 \\
\hline 160 & 15,68 & 10,01 & 340 & 15,65 & 10,03 \\
\hline 180 & 15,67 & 10,02 & 360 & 15,68 & 10,02 \\
\hline \multicolumn{7}{|c|}{ Second crank pin } \\
\hline 20 & 33,88 & 4,635 & 200 & 36,79 & 4,267 \\
\hline 40 & 40,11 & 3,915 & 220 & 40,15 & 3,910 \\
\hline 60 & 65,20 & 2,408 & 240 & 65,25 & 2,406 \\
\hline 80 & 89,20 & 1,760 & 260 & 89,27 & 1,759 \\
\hline 100 & 105,16 & 1,493 & 280 & 105,11 & 1,494 \\
\hline 120 & 109,86 & 1,429 & 300 & 109,84 & 1,429 \\
\hline 140 & 102,80 & 1,527 & 320 & 102,82 & 1,527 \\
\hline 1 & 2 & 3 & 4 & 5 & 6 \\
\hline 160 & 85,10 & 1,845 & 340 & 85,19 & 1,843 \\
\hline 180 & 60,19 & 2,608 & 360 & 60,27 & 2,605 \\
\hline & \multicolumn{7}{|c|}{ Third crank pin } & \\
\hline 20 & 1,03 & 152,9 & 200 & 1,03 & 152,8 \\
\hline 40 & 0,94 & 166,6 & 220 & 0,94 & 167,2 \\
\hline 60 & 0,91 & 173,4 & 240 & 0,91 & 173,0 \\
\hline 80 & 0,95 & 165,9 & 260 & 0,95 & 165,5 \\
\hline 100 & 1,04 & 151,0 & 280 & 1,04 & 151,0 \\
\hline 120 & 1,13 & 138,8 & 300 & 1,13 & 138,5 \\
\hline
\end{tabular}

\begin{tabular}{|l|l|l|l|l|l|}
\hline 140 & 1,18 & 132,7 & 320 & 1,19 & 132,3 \\
\hline 160 & 1,18 & 133,0 & 340 & 1,19 & 132,3 \\
\hline 180 & 1,12 & 139,6 & 360 & 1,13 & 139,5 \\
\hline
\end{tabular}

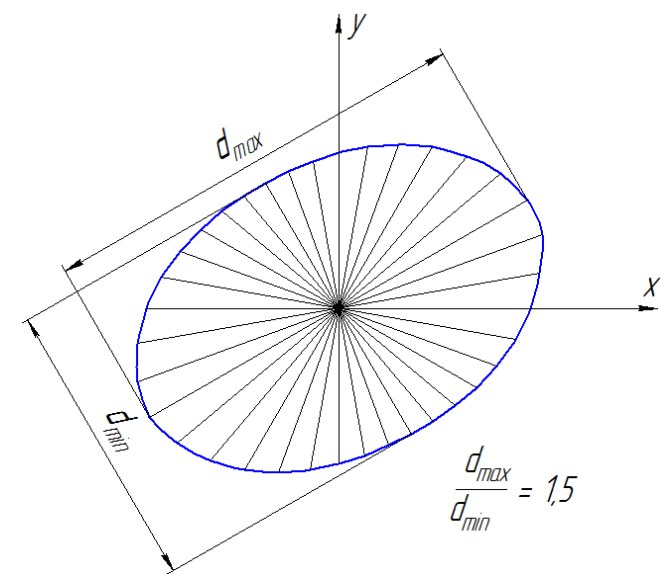

Fig. 4. The out-of-roundness of the cross section strain of the second crank pin

force $P$ (Fig. 5). On the basis of the results obtained earlier, the second crank pin of the crankshaft, which is rotated by $120^{\circ}$, was accepted as a dangerous section. The results of the analysis are presented in Table 4.

Table 4 . The cutting forces and strain of the crankshaft pin

\begin{tabular}{|c|c|c|}
\hline $\mathrm{P},(\mathrm{N})$ & $\delta \cdot 10^{5},(\mathrm{~mm})$ & $\mathrm{C} \cdot 10^{-5},(\mathrm{~N} / \mathrm{mm})$ \\
\hline 50 & 34,99 & \\
\hline 100 & 69,97 & \\
\hline 150 & 105 & \\
\hline 200 & 139,9 & \\
\hline 250 & 174,9 & \multirow{3}{*}{1,429} \\
\hline 300 & 209,9 & \\
\hline 350 & 244,9 & \\
\hline 400 & 279,9 & \\
\hline
\end{tabular}


It should be noted that the elastic strain of the crankshaft pins under the action of cutting forces are significant, which will not allow the necessary shape accuracy.

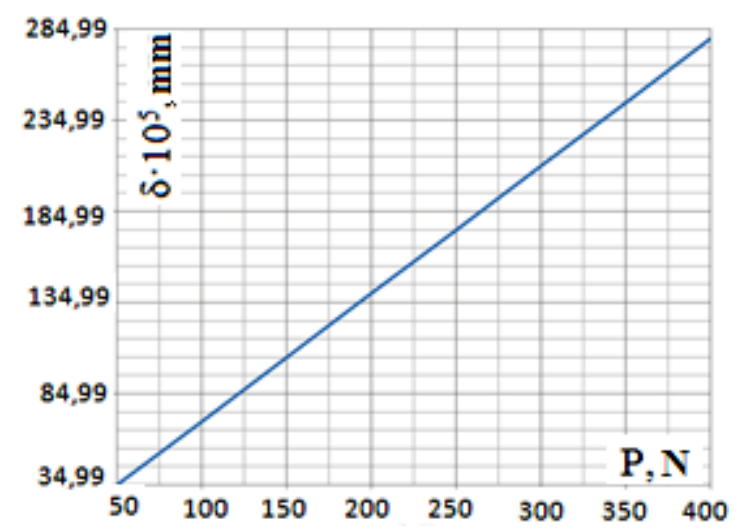

Fig. 5. Dependence of the cross section strain of the crank pin $\delta$ from the resultant cutting force $P$ during grinding

Therefore, the normative condition to ensure the necessary accuracy of machining crankshafts is the use of grinding steady rests of various designs [17].

\section{DEVELOPMENT THE CONSTRUCTION OF THE GRINDING STEADY REST}

To improve the quality and accuracy of the machined connecting rod journal (crank pin), as well as to level the harmful effect of the cutting force on the above parameters, the original design of the following grinding steady rest was designed (Fig. 6).

The principle of action of the rest is shown in Fig. 7.
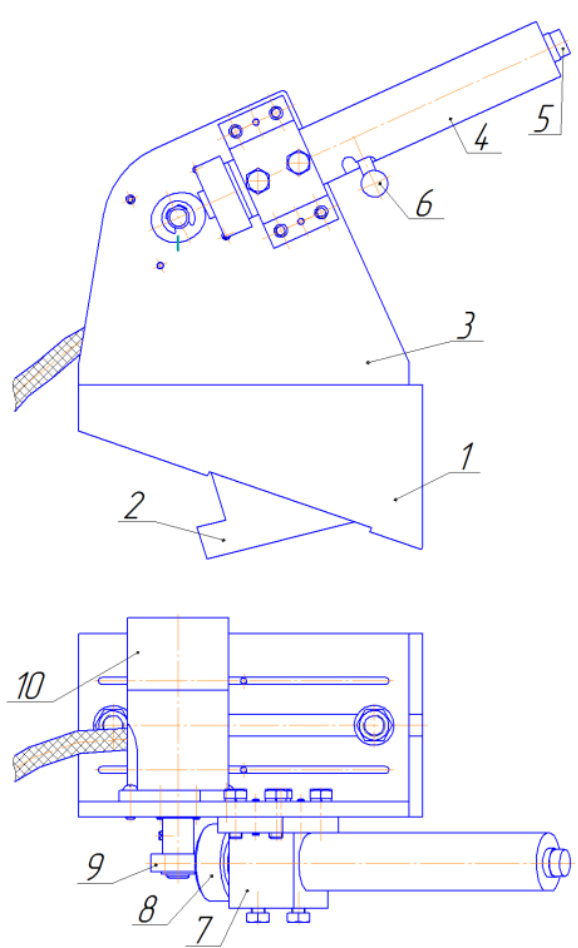

Fig. 6. Construction design of the following grinding steady rest: 1 - bearing plate; 2 - clamp strap; 3 - rest body; 4 - barrel; 5 - plunger; 6 - pin lock; 7 - flange; 8 screw-nut; 9 - profile cam; 10 - servomotor.

The rest is fastened to the machine bed with the help of a clamp strap 2, installed from below the bearing plate 1 . A movable rest body 3 is fastened on the bearing plate 1 . A flange 7 with a barrel 4 and a servomotor 10 are mounted on the body. A preliminary retraction of the plunger 5 of the rest when changing the workpiece is carried out using a pin lock 6.

The main detail in the design of the reste is the profile cam 9 (Fig. 6).

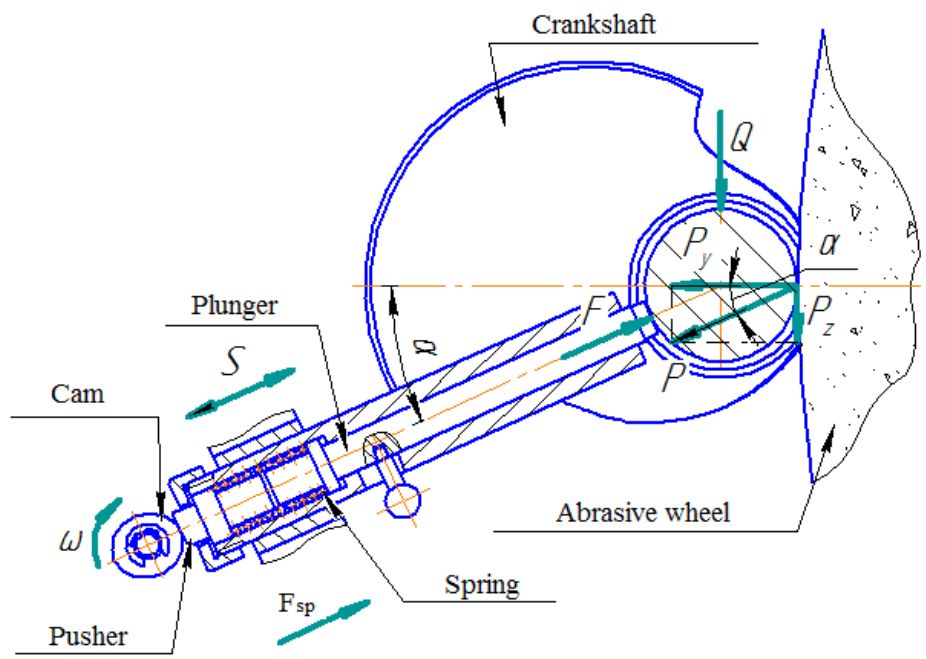

Fig. 7. Diagram of the work of the following grinding steady rest: $P y, P z$ - cutting force components; $P$ - closing cutting force; $Q$ - crankshaft weight; $F$ - balancing force; $S$ - plunger movement; $F_{s p}$ - initial spring strain force; $\omega$ - angular velocity of the cam rotation; $\alpha$ - angle between the closing cutting force $P$ and the vertical plane 
The cam profile completely repeats the out-ofroundness profile of the crank pin strain depending on the grinding force applied to it (Fig. 4).

The cam rotates with the help of an servomotor 10 , while moving the pusher, which through the spring moves the plunger 5 with the carbide plate. The plunger applies a balancing force $F$ to the crankshaft pin thereby reducing its elastic strain. The return of the plunger to its original position, as well as the constant contact of the pusher with the cam provided by the spring. The spring stiffness and the initial pressing force are regulated by the screw-nut 8. An important condition for effective work of the rest is the establishment of the initial position of the cam with respect to the crank pin (connecting rod journal) and the subsequent rotation of them with the same frequency.

The angle $\alpha$ between the closing cutting force $P$ and the vertical plane can be determined by the formula (11)

$$
\alpha=\arctan \frac{P_{z}}{P_{y}} .
$$

An important step in the project is to determine the dimensions and spring stiffness.

The spring pressing force for maximum strain can be determined by the formula (12):

$$
F_{3}=\frac{F_{2}}{(1-\delta)},
$$

where

$F_{2}-$ spring force at strain working;

$\delta$ - relative inertia gap.

The critical speed of displacement of the spring movable end is determined by formula (13):

$$
V_{c}=\frac{\tau_{3} \cdot\left(1-\frac{F_{2}}{F_{3}}\right)}{\sqrt{2 \cdot G \cdot \rho} \cdot 10^{-3}},
$$

where

$\tau_{3}$ - maximum shear stress of the spring;

$G-$ modulus of elasticity in shear;

$\rho$-dynamic material density.

The next step is to check the uptime condition for $1 \cdot 10^{4}$ hours (14):

$$
\frac{V_{\max }}{V_{c}}<1,
$$

where

$V_{\max }-$ maximum conveying speed of the spring movable end.

The correctness of the spring choice will be the fulfillment of the condition (14).

And at the end to ensure the rigidity of the rest design and qualitative of the crankshaft processing, it is important to determine the spring stiffness (15):

$$
c=\frac{F_{2}-F_{1}}{h},
$$

where

$h$ - working stroke of the spring;

$F_{l}$ - force of prior deformation.
Adequate design calculation will allow to make the original construction of the following grinding steady rest.

Such an machine device will allow to automate the process of grinding the crankshafts taking into account the compensation of the problems of the technological process, which are caused by the peculiarities of the profile of the crankshaft component part. And also this rest will improve the accuracy of processing and reduce its cost.

\section{CONCLUSIONS}

The crankshafts of internal combustion engines are responsible and stressed parts that operate under the influence of dynamic loads. The operating conditions of the crankshafts and associated engine parts require precise performance of the dimensions and the correct mutual position of the individual elements. To meet such challenges the following has been accomplished:

- The considered methods of initial parameters and simulation modelling. The possibility to determine the deflections and rigidity of crankshafts in any section is proved. Under such arrangement to determine the optimum cutting parameters for the round infeed grinding cycle has been possible.

- The design of the following grinding steady rest is developed. This machine device allows to compensate the cutting force effect on the elastic strain of the crankshaft, depending on the change in its rigidity. It is considered that the rigidity varies depending on the angle of rotation of the part.

Further research is planned to priorities time with the modeling issues and parametric optimization of the following grinding steady rest design for this type of parts.

\section{REFERENCES}

1. Karpus V, Ivanov V, Dehtiarov I. et al. Technological assurance of complex parts manufacturing. In: Ivanov V. et al. (eds.) Advances in Design, Simulation and Manufacturing. DSMIE-2018. Lecture Notes in Mechanical Engineering, 2019: 51-61. https://doi.org/10.1007/978-3-319-93587-4_6

2. Stepanov M, Ivanova L, Litovchenko P, Ivanova M. Basova Y. Model of thermal state of the system of application of coolant in grinding machine. In: Ivanov V. et al. (eds) Advances in Design, Simulation and Manufacturing. DSMIE 2018. Lecture Notes in Mechanical Engineering, 2019: 156-165. https://doi.org/10.1007/978-3-319-93587-4 17

3. Haruyoshi K. Technical developments and recent trends in crankshaft. Materials. Kobelco technology review, 2005; 26: 37-42

4. Crankshafts. Automotive Components Material SELECTION (Corus Engineering Steels_UK). Electronic resource (last conversion 16/06/2018) 
https://www.fsb.unizg.hr/miv/MSUI/KonMot/KonMo t_2014/Automotive\%20Components_Material_SELE CTION_(Corus\%20Engineering\%20Steels_UK).pdf

5. Tóthová M, Pitel' J. Simulation of Actuator Dynamics Based on Geometric Model of Pneumatic Artificial Muscle. 11th International Symposium on Intelligent Systems and Informatics (SISY) 2013: 233-237. https://doi.org/10.1109/SISY.2013.6662577.

6. Dereszewski M. Validation of failure detection by crankshaft angular speed analysis under sea waving conditions. Diagnostyka. 2014;15(3):59-63

7. Grytsyuk AV, Abramchyk FI, Vrublevskyi AN. Metodika opredeleniya pokazatelej dizelya 4DTNF1 pri dorozhnyh ispytaniyah Investigations [Method for determination of 4DTNF1 diesel indicators for road tests]. Automobile transport. 2013; 33: 44-49. Russian. http://dx.doi.org/10.29354/diag/10.29354/diag/90279

8. Karpus VE, Ivanov VA. Locating accuracy of shafts in V-blocks. Russian Engineering Research, 2012; Vol. 32(2): 144-150.

https://doi.org/10.3103/S1068798X1202013X.

9. Chiliński B, Zawisza M. Analysis of bending and angular vibration of the crankshaft with a torsional vibrations damper. Journal of Vibroengineering 2016; 18(8): 5353-5363.

https://doi.org/10.21595/jve.2016.17923

10. Murawski L, Charchalis A. Analysis methods of crankshaft's stiffness characteristics. Journal of KONES Powertrain and Transport, 2013; 20(1): 219226.

11. Alexandrov AV. Resistance of materials: Proc. For universities. 3th. ed. Moscow. High school, 2003. Russian

12. Han ST, Shu XD, Shchukin V, Kozhevnikova G. Multi-objective optimization of process parameters of multi-step shaft formed with cross wedge rolling based on orthogonal test. 2018 International Conference on Material Strength and Applied Mechanics. IOP Conf. Series: Materials Science and Engineering, 2018; 372: 012044. https://doi:10.1088/1757-899X/372/1/012044

13. Montazersadgh FH, Fatemi A. Stress Analysis and Optimization of Crankshafts Subject to Dynamic Loading. A Final Project Report Submitted to the Forging Industry Educational Research Foundation and American Iron and Steel Institute. Toledo; 2007.

14. Khasnis V, Ukhande M, Tilekar G, Mane R, Shegavi G. Crankshaft design optimization to improve dynamic balancing and fatigue strength. International Journal of Automotive Engineering, Society of Automotive Engineers of Japan, 2015; 6(2): 59-66. https://doi.org/10.20485/jsaeijae.6.2_59

15. Talikoti1 BS, Kurbet SN, Kuppast VV and et. Static structural analysis of 2-cylinder crankshaft using ANSYS. International Journal For Technological Research In Engineering 2015; 3(2): 242-245

16. Talikoti1 BS, Kurbet SN, Kuppast VV. A review on vibration analysis of crankshaft of internal combustion engine. International Research Journal of Engineering and Technology 2015 2(9): 1943-1948.

17. Self-Centering Steady Rests for turning, milling and grinding. SMV Autoblok. Electronic resource (last conversion 18/06/2018) http://www.smwautoblok.de
Received 2018-08-07

Accepted 2018-11-15

Available online 2018-11-22

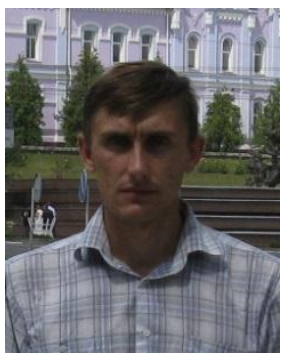

Alexey KOTLIAR (ORCID 0000-0001-7664-0395), PhD, Docent, Associate Professor at the Department of technology of mechanical engineering and metal-cutting machine tools of the Educational and scientific institute of mechanical engineering and transport of the NTU «KhPI», Kharkov, Ukraine.

Main directions of scientific research: enhancement of functional capabilities and an increase productivity metal-cutting machines; multi-criteria optimization of technological processes and systems.

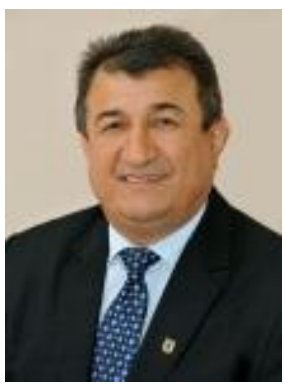

Magomediemin GASANOV (ORCID 0000-0002-2161-2386), $\mathrm{PhD}$, Professor of NTU "KhPI", Vice-rector for scientific-andpedagogical work of the NTU «KhPI», Kharkov, Ukraine.

Main directions of scientific research: enhancement of functional capabilities and an increase productivity metalcutting machines; multi-criteria optimization of technological processes and systems, object and equipment reliability.

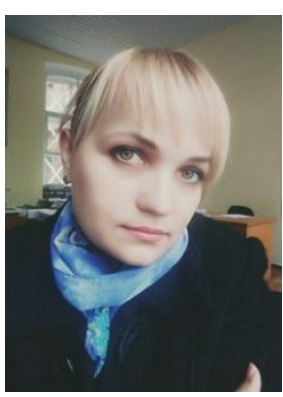

Yevheniia BASOVA (ORCID 0000-0002-8549-4788), PhD, Associate Professor at the Department of technology of mechanical engineering and metal-cutting machine tools of the Educational and scientific institute of mechanical engineering and transport of the NTU «KhPI», Kharkov, Ukraine.

Main directions of scientific research: physicotechnical processing methods, engineering technology, programming, CAD / CAM / CAE / CAPP systems, optimization and modelling in mechanical engineering processes for technological prognostication in innovations.

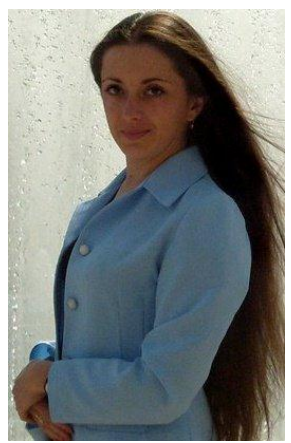

Olga PANAMARIOVA

(ORCID 0000-0003-4080-4532), $\mathrm{PhD}$, Associate Professor at the Department of hydraulic machines of the Educational and scientific institute of mechanical engineering and transport of the NTU «KhPI», Kharkov, Ukraine.

Main directions of scientific research: mechanical engineering, hydraulic drive of technological machines, engineering technology, programming, CAD / CAM / CAE / CAPP systems. 


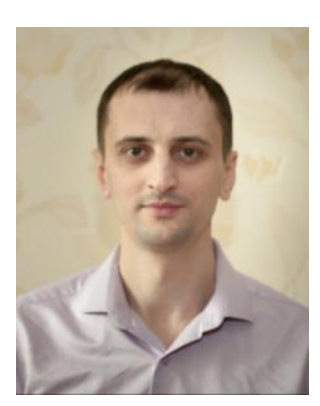

Sergii GUBSKYI (ORCID

0000-0001-7797-9139), PhD,

Docent, Associate Professor at the Department of lifting and transport machines and equipment of the Educational and scientific institute of mechanical engineering and transport of the NTU «KhPI», Kharkov, Ukraine.

Main directions of scientific research: safety operation improving of handling machines, operational suitability determining of crane metal structures using integrated approach of numerical methods and non-destructive testing methods (including based on coercive force). 